10s. 6d. ; and the fee for a post-mortem examination, including report to the coroner, being $£ 1$ 1s., such fee being exclusive of the fees paid, under the Coroners Acts, for giving evidence at the inquest if held.

19. That it shall be illegal for any registrar of deaths to give a book of forms, or a form, of the certificate of stillbirth until he shall have received from the practitioner desiring such book of forms a written request signed by the applicant in the presence of the registrar, and until he shows to such registrar his certificate of registration as granted by the General Medical Council.

20. That it be illegal for any coroner, procurator fiscal, or registrar of deaths to use any form of certificate other than that provided by the Registrar-General's Office.

21. That each registrar of deaths in the United Kingdom shall notify the sanitary authority all particulars required by such authority concerning all the stillbirths registered by him.

22. That it shall be illegal for any person to keep the body of a stillborn child in any dwelling piace or in any other place for more than four days, unless by order of the coroner or procurator fiscal.

23. That when a coroner orders an inquest to be held concerning a supposed stillborn child, the jury summoned shall consist of five persons only.

24. That the present law be altered so that the plea of pregnancy, and not the plea of quickening, shall be a valid reason why a pregnant woman shall not, until after she shall be confined, suffer capital panishment.

25. That the criminal law relating to infanticide be amended, so that for the purpose of conviction "complete birth" be not required, but proof only that the child was living during birth, and that it has died from criminal violence inflicted during or after birth.

In connection with this public question, it must always be remembered that in almost all stillborn cases, only those present at the birth can be certain as to whether the stillbirth is due to criminal causes. It is a question of fact only. It is my earnest wish that the above recommendations be discussed by all the Branches of our Association, and by medical and coroners' societies, and that such send copies of resolutions in favour of registration and inspection of stillbirths to their local members of Parliament. It is only by bringing this important question prominently to the front in these days of pressure of public business that we can expect to secure legislation. I need only refer to the work done by Sir Charles Cameron, M.D., and Sir Walter Foster, M.D., in connection with the Select Committee of the House of Commons on Death Registration to show that we may count upon their continued efforts. In order that any one who wishes to work up this subject may do so, I shall refer such to the following works mentioned beneath. I cannot let this occasion pass without publicly expressing my thanks to those of Her Majesty's Consuls and Ambassadors who have supplied me with facts relating to the laws of foreign countries bearing upon the inspection and registration of stillborn children. [The Burial Laws, by Little (Shaw and Sons); The Law kelating to the Registration of Births, Deaths, and Marriages, by W. C. Glen and A. Glen; Jervis On Coroners, fifth edition (Sweet and Sons); Seton's Practical Analysis of the Acts Relating to the Registration of Births, Marriages, and Deaths in Scotland (Edmonston and Douglas); Nomenclature of Diseases second edition (Royal College of Phrsicians, London); Regulations issued by the Registrars-General of England, Scotland, and Ireland to Registrars and Superintendent Registrars of Deaths; Official List of the Registrars-General, thoving the Occupation of Registrars; itillbirth Interments, Parliamentar Return 0. Protection of Infant Life, Parliamentary Report No. 372, July, 1871 . Death Certification, Parliamentary Report No. 373, Centember 1893. Stillbirths in England and other Countries, Farliamentary Return No, 279, June, 1893; Registration of Births and Deaths Act (England), 1874 ; Registration of Births and Deaths Act (Ireland), 1880; an Act to provide for the Better Registration of Births, Deaths, and Marriages (scotland). 1854.]

Graman Mrdicax Press Association.-The German Medical Press Association, which came into existence at the meeting of the German Scientists and Physicians, held in Vienna in September, 1894, now includes the editors of all the leading medical journals published in the German language. The object of the Association is to increase the influence of the medical press, and safeguard its interests, and on all occasions to promote its proper representation, especially at congresses and similar meetings. The Association will meet this year in Berlin, under the presidency of Professor Eulenburg.

\section{THE PROPHYLAXIS OF INFLUENZA}

By J. G. SINCLAIR COGHILL, M.D., F.R.C.P.EDIN., Senior Physician fto; the Royal National Hospital for Consumption,

THr annual recrudescence of influenza in epidemic form with more or less virulence renders its prophylaxis a matter of extreme urgency. My experience in this connection has confirmed the opinion that in quinine we havean almost unexceptionable preventive of the scourge. I was first led to the use of this remedy by recalling to memory a passage I had noted some years ago in a very amusing and interesting book by De Windt, entitled From Pekin to Paris. The author made the observation that the frequent change of encampment of the nomad Tartar tribes of the Central Asian steppes was not so much determined by the necessity for fresh pasture as by the circumstance that, if the encampment were not changed at intervals, influenza attacked them, and developed with increasing intensity until change of location was effected. This, of course, points to a materies morbi of telluric origin intensified by what French pathologists term encomblement, at first endemic and then epidemic in character. This agrees with the natural history of the epidemics of influenza of recent years. It was called by the Russians the "Chinese Influenza," from its 'Tartar cradle, and, when passed on its pestilential career to the west, became the "Russian Influenza" to the Germans and other nations of Northern Central Europe.

The following experience will, I think, show that my opinion of the protective properties of quinine in influenza is well founded. On the appearance of the epidemic in October. 1891, I was consulted by the principals of a large educational establishment, mostly patronised by foreign pupils, as to whether I would advise them to close the institution, or could recommend some efficacious preventive. The school consisted of nineteen resident pupils, besides teachers, servants, and day pupils. I advised that every resident inmate of the house should take immediately after breakfast a gr.v pill of sulphate of quinine. This injunction was strictly obeyed during the prevalence of the epidemic, with the result of complete exemption. One of the domestic servants who went $\tau 0$ an adjacent town to attend her mother, who died of the epidemic, returned to her duties evidently suffering from it, but did not communicate it to any of the other inmates of the house.

A singular corroboration of this protective rotency was afforded more recently in this same institution. All the inmates were put upon the matutinal quinine regimen as formerly, with the exception of one of the principals, who was induced to refrain, from other considerations in connection with her health. The result was that she alone took influenza in a rather severe form, but did not communicate it, not even to her colleague who shared her room throughout, but who was protected by quinine. My own personal experience is further corroborative. In the same epidemic of $189 \mathrm{l}-2$, I similarly placed my whole household, consisting of fourteen persons, on quinine. In consequence of my mind being very much preoccupied with professional and other anxieties, I neglected after a few days to take my breakfast dose of quinine, the result of which was that I contracted the disease trom some of my patients, and in a very severe form, with pneumonic consolidations of the right base. My tenperature for nearly a week was recorded nightly at $103.8^{\circ}$ I was so gravely ill that my solicitor was sent for, and spent more than an hour at my bedside. He was unable to rise next morning, and the disease spread to his family and servants; they all had severe pulmonary complications, and his wife succumbed. No other member of my family or household was attacked, because, as I am strongly convinced, they were protected by quinine.

I have since seen, in very many instances, further and equally convincing proofs of this prophylaxis. I am further impressed with the fact that the symptoms of influenza more rapidly yield to quinine with salicin if there be muscular or joint pains, or with ammonia in pulmonary complications, with a large administration of old dry champagne, for which indeed there seems to be almost as strong a craving as for air in the agonies of dyspnca, than to so-called antipyretics, or 
other depressants, which not only retard the resolution of the morbid phenomena, but to which I largely attribute the subsequent debility and protracted convalescence which characterise so many cases of this ailment.

\section{INFLUENZA IN AN INFANT, COMPLICATED WITH HYPERPYREXIA.}

BY JOHN McCAW, M.D.,

Physician to the Belfast Hospital for Children.

I wAs asked to see baby P., aged 4 months, on March 18th. He had been ailing for two days with a slight cough, which evidently gave him pain; he was restless and peevish, and " his skin was hot." The temperature was 101"; the pulse good at 98 ; there was good deal of coryza, and he was evidently tender generally over the body as he cried when handled; the bowels were a tritle over-active and the motions curdy ; examination of the chest revealed moderate bronchial catarrh. The mother and another child were suffering from influenza of a mild kind, with symptoms akin to those of he baby.

Confinement to one room, a simple sedative diaphoretic mixture, and careful regulation of the diet were ordered, and everything seemed to progress favourably until the evening of March 20th, when violent general convulsions supervened at 8.P.M. As I live some distance away, a doctor living quite close was called in in the emergency. He treated the baby skilfully and with success, the convulsions being subdued in two hours. However, they returned again at 2 A.M. on March 21st, and I was sent for. I arrived at 3 A.M. and found the baby generally convulsed. I gave a whiff or two of chloroform and 5 grains of bromide of soda, the former bringing relief for a time, but the convulsions returned as its effect wore off. The temperature in the rectum was $107.6^{\circ}$ To make sure I took it again with another thermometer, and the same point was reached. Here, then, we evidently had the cause of the convulsions; and now the question arose, how was this temperature to be brought down?

$A$, bath was got ready, the water being comfortably warm to the hand (I regret there was not a bath thermometer in the house), and the child, completely stripped, was put in, the water covering him almost entirely. At this time his respirations were 90 per minute, and pulse about 200 . By the addition of cold water the bath was now somewhat quickly lowered until a point was reached at which it felt decidedly "cool." Gradually the child ceased to twitch, the respirations fell to 35 , and the pulse to 110 a minute, at the same time becoming fuller and better. The following is the record of the temperature:

\begin{tabular}{|c|c|c|c|c|c|c|}
\hline. $\mathrm{M}$ & & & & & & 107 \\
\hline 4.10 А. M. & ", & ") & $"$ & $\cdots$ & ... & $105.0^{\circ} \mathrm{F}$. \\
\hline $4.15 \mathrm{~A} . \mathrm{M}$. & " & ", & " & $\cdots$ & $\cdots$ & $1032^{\circ} \mathrm{F}$. \\
\hline $\begin{array}{l}4.20 \text { А.M. } \\
4.30 \text { А.M. }\end{array}$ & " & 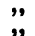 & ", & $\ldots$ & $\ldots$ & 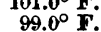 \\
\hline
\end{tabular}

At this point he was taken out, and he immediately fell into a sound sleep, in which I left him.

I visited him again at 11.30 A.M., when I was informed he had slept soundly for four hours or so, but since he awoke had gradually become restless and hot. The temperature had risen again to $105.6^{\circ}$, the respirations to 90 , and the pulse to 180 , so I again had recourse to the cold bath.

$$
\begin{aligned}
& 11.30^{\circ} \text { A.M. temperature in the rectum ... } \quad \ldots \quad 1 c 5.6^{\circ} \mathbf{F} \text {. } \\
& \begin{array}{lllllll}
11.35 \text { A.M. } & \| & \| & & \ldots & \ldots & 105.0^{\circ} \mathrm{F}
\end{array}
\end{aligned}
$$

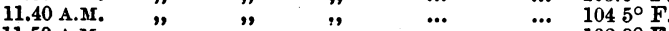

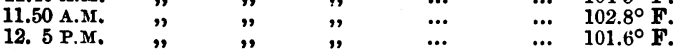

As he was getting pinched-looking at this point he was taken out, and while he was evidently relieved of all his urgent symptoms to a considerable extent, the effect of the bath was not so marked as on the previous occasion; he slept for two hours and then relapsed into much the same state as before. I saw him again the same evening at 945 , and as his temperature at this time was $106^{\circ}$, I repeated the cold bath, with the following results :

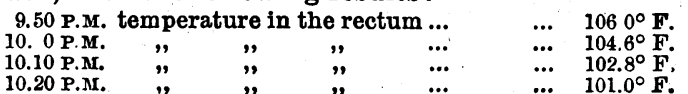
10.20 P.M. $" \Rightarrow \quad " \quad$ " $\quad \ldots \quad \ldots 101.0^{\circ}$ F. was now obliged to take him out as he was gotting pinched-looking and cold. I saw him the following morning : he had a restless night, and was now evidently weaker. The temperature was $1046^{\circ}$ and the pulse 180. Careful examination of the chest revealed nothing but moderate bronchial trouble, there being no evidence of pneumonia to be found. He became gradually weaker and died the same evening, quietly and without any return of convulsions. With the +xception of the convulsions brain symptoms were absent throughout. After the first bath 1-grain doses of quinine hsdrobromate and phenacetin were given every three hours, but without effect on the temperature.

\section{ON THE REMOVAL OF ADENOID VEGETATIONS IN THE NASO-PHARYNX,} WITH A DESCRIPTION OF A NEW FORM OF SCRAPER.

BY H. BENDELACK HEWETSON, M.R.C.S.ENG., F.L.S., Ophthalmic and Aural Surgeon to the Leeds General Infirmary.

THat most excellent early form of scraper suggested by Dr. Hartmann, of Berlin, I have employed since its invention some years ago, but it now seems to me to require some modification. Hartmann's scraper is stirrup-shaped and triangular in form; the double semi-sharpened edge being set at somewhat less than a right angle to the shaft, pointing towards the posterior nares.

It frequently happens that vegetations exist in such a position in the naso-pharynx that the non-scraping portion of the instrument is presented to them, and it is only by awkward manœuvring that the scraping edge can be brought to bear on the vegetations lying behind, and in some cases below, the scraper when in situ behind the soft palate.

I have tried to design a scraper which would be quite blunt towards the soft palate, and set at an obtuse angle on the shaft. It presents a semicircular scraping double edge, which can by an alteration of pressure be made to scrape with its presenting curve upwards, backwards, and even downwards, attacking adenoids even occupying the pharynx at the same introduction of the instrument. I have used it now frequently, and find it quite comes up to my expectation. In some instances I have removed with it large pendulous vegetations, for the removal of which I have previously invariably employed Loewenberg's forceps. Whatever form of scraper we use, these forceps must continue to be required in removing some of the growths effectively.

I believe that to remove post-nasal adenoid vegetations effectively an anæsthetic must be used, and, after some years of trial, I have come to the conclusion that ether, skilfully administered by means of Clover's inhaler, is the best and the safest. I never allow the patient to be put deeply under its influence, and certainly never get rid of the cough reflex. It is wise to recollect that. frequently these conditions are associated with nasal stenosis and confirmed mouth breathing, and that greater care than usual is needed in the administration of the anæsthetic.

I used to operate with the patient's head hanging back over the end of the operation table; but I found that there was a danger of asphyxia from bending of the trachea over the cervical vertebræ in persons with long necks; in fact, $I$ observed in some cases that the patients ceased to breathe when the head was thrown back over the end of the operation couch in the position chosen by some operators. I find that a safe and convenient position is to remove all pillows on a level couch and allow the head of the patient to roll over towards the operator to the right, so that the right hand of the operator may be used whilst his left steadies the head.

The instrument I have suggested is readily introduced behind the soft palate, and, used as I have described, a few rapid and well-directed lateral movements suffice to scrape 